\title{
32 DEFINITION OF A GENERIC CAPABILITY MODEL FOR EXTENDED ENTERPRISE DESIGN FOR MANUFACTURE
}

\author{
Ip-Shing Fan ", Nicola J. Ward, Stephen C. Cooper \\ Kamal Sehdev \\ Cranfield University, UK
}

\section{Gareth Williams British Aerospace Airbus Ltd, UK}

\begin{abstract}
Information exchange in Extended Enterprise is difficult, as it is rare for two organisations to have a common communication protocol, especially early in the supply relationship. This research develops a generic definition of supplier capability for machining suppliers in the aerospace industry. This model presents a mechanism for the structured transfer of manufacturing information to design. The implementation of the model is in a database that can be filled with information using Internet technology.
\end{abstract}

\section{INTRODUCTION}

In a vertically integrated company where manufacture is executed 'in house', the engineering design team has access to the shop floor; manufacturing expertise is available to support the product development process. In complex engineering products it is common that much of the manufacture of components and subassemblies is outsourced to the supply chain rather than completed 'in house' (Vernadat, 1996). Design for manufacture currently depends heavily on the tacit knowledge and communication between engineers. This communication is made difficult by outsourcing, with suppliers not always available in the early stages of product development. Information about suppliers' capabilities is not necessarily documented and engineering trade off must therefore be based on the experience and knowledge of the 'in house' design team.

\footnotetext{
- Cranfield University, Cranfield, Bedford, MK43 OAL, UK, e-mail: isfan@yahoo.com
} 
The nature and type of manufacturing information that the design team requires is situation dependent (Court, 1885; Kuffner, 1991). Design engineers require information on supplier manufacturing capability in order to support design for manufacture, and understand how production constraints may affect the product design (Boothroyd, 1994; Corbett, 1991). Manufacturing engineers require details of process and equipment parameters in order to interpret this manufacturing capability. The commercial activities of the Original Equipment Manufacturer (OEM) also have a requirement for capability information, when searching for suppliers to manufacture components. However, the supplier capability information that is required by the various members of the design team is not easily accessible. Court (Court, 1993) estimated that $20-30 \%$ of designers' time is spent searching for information. A subsequent paper concludes that the supplier capability information available to the designer is so patchy or unreliable that some assumptions or judgements must be made that go beyond the available evidence (Court, 1995). Meanwhile, Konda (Konda, 1992) observed that the advantage of outsourcing manufacture is often countered by concessions and design modifications.

A major problem in assimilating manufacturing capability information is the number of different formats that are used by suppliers, which is immediately evident from their marketing literature. The development of a standard representation, or supplier capability model, has been a major focus of the work completed in the EPSRC funded research project, 'Integrating design and manufacturing knowledge in the extended enterprise (INDEMAND)'. The benefits that may be provided by a standard supplier capability model are evident from the illustration of the INDEMAND concept (Figure 1). The standardised model allows the automated capture and collation of the capabilities of multiple suppliers by the OEM. The resulting database may then be queried directly or accessed by other applications, such as a design for manufacture tool.

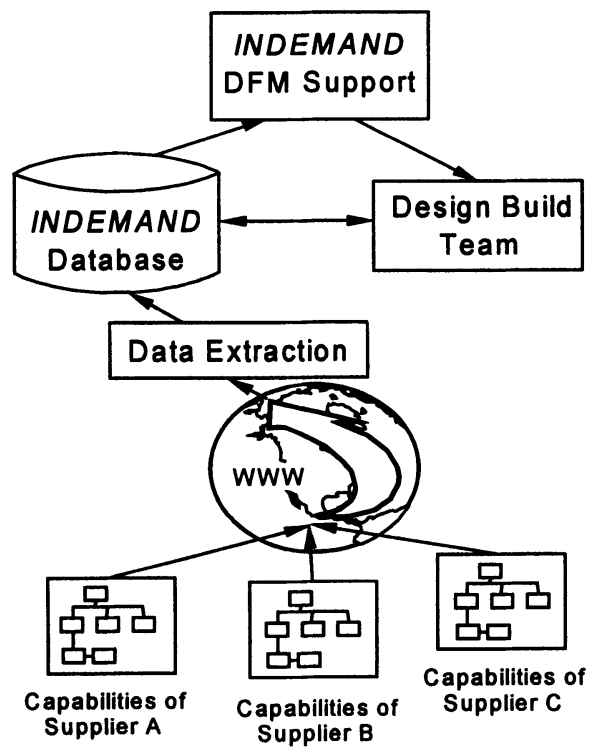

Figure 1 - The INDEMAND Concept 


\section{CIVIL AIRCRAFT INDUSTRY REQUIREMENT FOR SUPPLIER CAPABILITY INFORMATION}

The development process for civil aircraft is complex. The design phase typically involves more than 2000 engineers, who are located in geographically separated teams (Bond, 1992; Cooper 1998). In this sense it is typical of the extended enterprise, which is described by Busby (Busby 1993) as, "a combination of firms involved in the process of supplying a certain good or service, and one in which the participants enjoy long term relationships among themselves." Within this network of companies, the product owner designs, markets and bears ultimate responsibility for the product whilst working with supplying partners who provide the sub-assemblies, components and particular processes. Effective product development within the extended enterprise requires communication between many groups of people within both the product owner and the suppliers. One part of this communication concerns the transfer of information concerning suppliers' capabilities. In order to understand what type of information must be communicated, and when, it is first necessary to appreciate a number of the characteristics of the industry.

\section{Component Characteristics}

Civil aircraft components are predominantly discrete, machined parts as opposed to standard items. This impacts upon the means by which the capabilities of suppliers can be represented. Standard parts exist prior to the start of product development. Standard parts suppliers can therefore express their capability using tangible attributes such as product quality, product price and delivery service, and the features and performance of the parts can be considered during product development. Suppliers of discrete parts cannot describe their capabilities in a simple form because until the contract is received and production has started the product is not tangible. Discrete parts suppliers must express their capability using the capabilities and constraints of the resources, and the skills and experience of the company. These capabilities are valuable to the product owner because they affect a supplier's ability to manufacture a particular design.

\section{Users of supplier capability information}

Within the aerospace product owner organisation, the three key groups that need to have access to supplier capability information are engineering designers, manufacturing engineers and procurement personnel. The information needs of these user groups influence the definition of the supplier capability model.

Engineering designers define the shape of the components and produce the data for manufacture in the form of manufacturing drawings and instructions. The designers negotiate with aerodynamics, stress and fatigue engineers, and specify the material to be used and the dimensions and features of the components. Design Handbooks provide the standards and general guidelines on the design parameters. The main areas where designers require supplier information concern:

- The limitations of the technologies that the potential or prospective suppliers have, so that different concepts can be evaluated with respect to the capabilities available. 
- Reducing manufacturing costs, where possible, by using Design For Manufacture (DFM) philosophies based upon the suppliers' capabilities.

- The general capability (or norm) of all the potential suppliers in the industry so that the design can be made as generic as possible, hence reducing costs if the existing or first supplier is changed for another supplier.

- The preferred cutter parameters of the suppliers, so that the number of cutters may reduced.

- The fixturing and tooling concepts used during manufacture, so that the placement of location and fixture lugs can be considered during design.

Manufacturing engineers ensure that parts can be made efficiently and are the technical interface between the designers and the suppliers. Once the design engineers have completed the design of a part, the manufacturing engineers sign it off on behalf of the suppliers. Without knowledge of suppliers' capabilities the manufacturing engineers can only sign off a design based upon generic DFM information, and cannot assess it against the ability of the particular suppliers to manufacture the part. The manufacturing engineers need:

- To know the processes that the suppliers will use, and their constraints, so that product design has taken into consideration suppliers capabilities.

- An understanding of the manufacturing process plan used for previous designs. This would help the manufacturing engineers understand when the design is outside the limits of the current process.

Procurement is responsible for choosing the supplier and handling the bid tendering process. Procurement is also responsible for monitoring the capabilities of the suppliers. The supplier information must enable them to evaluate the:

- Overall commercial and manufacturing capabilities of a supplier in order to determine its suitability for a bid package.

- Current capacities of the supplier.

- Efficiency and performance of the supplier.

\section{Alternative Types of Product Development}

There are three different modes of product development in the civil aircraft industry: new product design; continuous design; and variant design. The general transfer of information amongst the activities of the OEM and supplier within these product development modes is illustrated in Figure 2. New product design, in which entirely new aircraft is developed is infrequent. Continuous design is concerned with ongoing development and improvement of the product once it is in service. This can include modifications that incorporate technical improvements to enhance the functionality of a component or be in response to requests from manufacturing for changes to ease production, reduce rework and costs, and shorten delivery time. Variant design is concerned with modifications that enable an existing product to complete a new mission. In a civil aircraft this may involve stretching the fuselage to accommodate more passengers and/or or strengthening the aircraft structure to allow more fuel to be carried and so provide an increased range. The engineering risk and the high cost of testing and certification encourage the design of variants, as opposed to new products, wherever possible. The mode of product development impacts upon the type of information that may be available from the supplier, for example, in continuous or variant design it may be important to understand the manufacturing process that is currently being employed by a particular supplier to fulfil a particular part. 


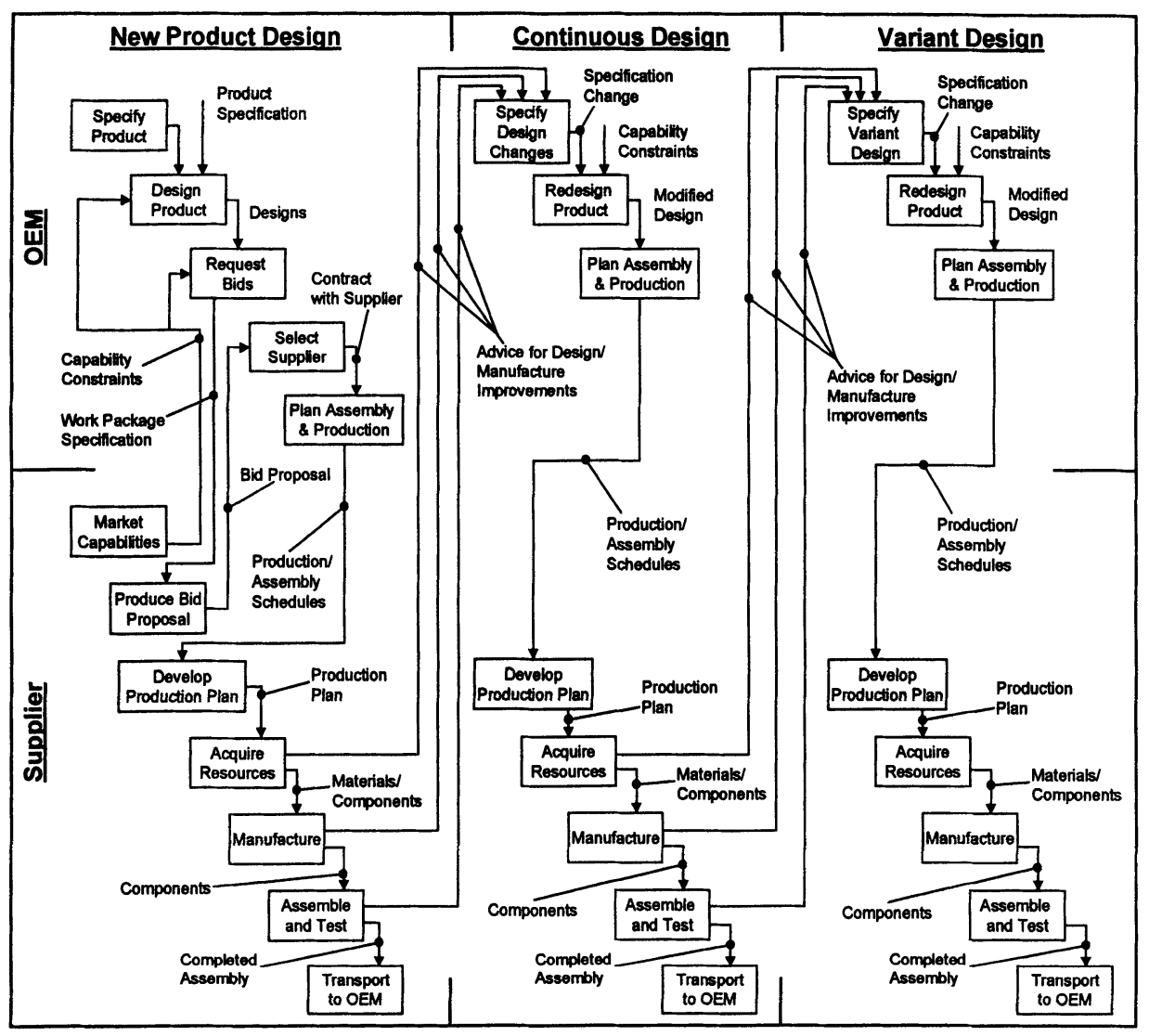

Figure 2 - Product development information flows

\section{Timing of Supplier Selection}

A further influencing factor on the availability of supplier capability information is the stage of the product development process at which the supplier is contracted. The intention of the product owner is to involve key suppliers as early as possible, preferably prior to the initial design. After the conceptual design is complete, additional suppliers may be assessed and selected. By the detail design stage it is expected that all suppliers are involved and understand the design requirements. The conditions of supply are agreed with the suppliers as part of the contract. In practice, commercial and technical reasons may bring new suppliers into the extended enterprise even at the manufacture and assembly stages. In this type of scenario it is important for the design to be completed based upon an understanding of the generic capabilities of the supply base.

\section{RELATED RESEARCH}

The first formal representation of supplier capability information can be found in a company's marketing literature. However each company represents their capability differently and the information that is included is insufficient to meet the full user 
requirements. The need for a more formalised representation of supplier capability has long been recognised and considerable research has been done in the area.

Lists of supplier selection criteria (Dickson, 1996; Ellram, 1990; Weber, 1993) indicate the general areas in which a prime contractor may wish to evaluate a supplier. However, they do not indicate the specific information that would be required from a supplier or provide a standard structure in which it may be communicated. This makes them, in isolation, unsuitable for collating and comparing the capabilities of different suppliers. GT-based approaches (SCRA, 1998; Candadai, 1996) do provide a standard format but require additional work from the supplier in codifying the parts that they are capable of manufacturing. It also became apparent during the research that suppliers may be unwilling to define their capability quantitatively in terms of part attributes. This was primarily because of concerns that such a representation would not adequately define their capability, not representing how the knowledge and experience of the company's engineers would be applied in a specific situation. Manufacturing resource models (Chang, 1990; Molina, 1994; Minis, 1996; Naish, 1997) avoid this problem by defining manufacturing capability in terms a companies equipment, which has known quantifiable specifications. Manufacturing resource models can also be extended to capture other aspects of the company, such as commercial factors, which are required by the various user groups within the prime contractor. Hence, conceptually, a supplier capability model based upon manufacturing resource models could meet the requirements outlined in the previous section. The major limitation is that current models have yet to be tested in general industry.

\section{DEVELOPMENT OF THE SUPPLIER CAPABILITY MODEL}

The purpose of the supplier capability model is to support those decisions that are made by the OEM during product development, which may impact upon the ability of the supplier to manufacture and provide the necessary components to the required standard. The first step in model development was to identify the decisions that the model must support. This was achieved though a review of the documents passed between the OEM and supplier during the product development process:

Pre-bid pro-forma - These are OEM forms that are completed by suppliers who wish to receive details of requests for bids. The OEM may use the information provided on these forms for pre-selection, in order to ensure that requests for bids are only circulated to suppliers that meet the necessary qualifying criteria. The content of these forms may therefore be taken to be representative of the characteristics that all suppliers must have in order for the OEM to consider working with them. A study of the pre-bid pro-forma of seven large complex engineering companies from the automotive, aerospace and shipbuilding industries was completed and an initial list of information to be contained in the model was developed.

Design Drawings - The design drawings represent the physical properties and features of the component to be manufactured. A study of the information included in typical design drawings of the collaborating OEM and an assessment of the 
published literature on product development were completed in order to identify the design decisions that the model must support.

Request for Proposals - The request for proposals specifies to the supplier the information that is to be supplied in the quotation and costing. This package may include the methods of manufacture, production quantities and production plan. The bid information that is typically circulated by the collaborating supplier was studied in order to refine further the content of the model.

Supplier Selection Criteria - Procurement personnel have their own guidelines against which suppliers are selected. These guidelines represent the difference between qualifying and order wining criteria. The evidence that the suppliers put forward in their proposals must demonstrate their ability to achieve these criteria. A study of the published literature in supplier tender and selection process was used to refine the list of information required to support supplier selection.

These documents represent a summary of the outcome of the relevant decisions that are taken by the OEM during product development. Their study enabled the definition of a mixed list of the information to be included in the supplier capability model and the design decisions that the model must support. This was then evaluated against the nature of a manufacturing company in order to identify the information that could be used to support the decisions. A complete list of the capabilities to be included in the supplier capability model was produced (Table 1).

The list of types of supplier capability indicates the information that must be contained in the supplier capability model. To allow implementation, the supplier capability model must be structured so as to enable economical storage and retrieval of the appropriate data. A proprietary relational database package was selected as the implementation technology. Therefore, a standard normalisation procedure was employed to decompose the list of supplier capability types into a structured, supplier capability model consisting of a number of related data tables.

Having defined the initial supplier capability model, further refinement was achieved by population with data from the collaborating suppliers. This led to a number of modifications being made to the data tables and their relationships. For example, the machine accuracy was removed from the specification of manufacturing equipment because suppliers were reluctant to provide this data in case it was misinterpreted as a reflection of tolerance capability. It was felt that a tolerance could not be allocated to a machine because the achievable tolerance is also affected by factors such as the skill of the manufacturing engineer, the condition of the machine and the complexity of the part. In order to provide an indication of the tolerance capabilities of a supplier, a field was added to allow the definition of the quality standards to which the available process are completed. Another example of a modification was the linking of material handling equipment to the machines that they can service. This was added to reflect the cellular manufacturing strategy employed by some supplier. The structure of the final supplier capability model is illustrated in Figure 3. 
Table 1 Types of supplier capability

\begin{tabular}{|c|c|c|}
\hline Category & Explanation & Examples \\
\hline $\begin{array}{l}\text { Experience } \\
\text { (representing } \\
\text { knowledge) }\end{array}$ & $\begin{array}{l}\text { The relationships that the } \\
\text { supplier has with customers } \\
\text { and the type of components } \\
\text { he has supplied to them. }\end{array}$ & $\begin{array}{l}\text { Customer, industry, component } \\
\text { type, component key } \\
\text { characteristics, materials, } \\
\text { processes used, sizes }\end{array}$ \\
\hline $\begin{array}{l}\text { Supplier } \\
\text { relationships }\end{array}$ & $\begin{array}{l}\text { The relationships that the } \\
\text { supplier has with his supply } \\
\text { chain. }\end{array}$ & $\begin{array}{l}\text { Raw material suppliers, standard } \\
\text { component suppliers, special } \\
\text { process suppliers, off load } \\
\text { suppliers }\end{array}$ \\
\hline $\begin{array}{l}\text { Technical } \\
\text { resources }\end{array}$ & $\begin{array}{l}\text { The processes, machines and } \\
\text { limitations of the machines } \\
\text { used during manufacture. }\end{array}$ & $\begin{array}{l}\text { Patterns, moulds, dies punches, } \\
\text { jigs and fixtures } \\
\text { Manual tools and machine tools } \\
\text { Specialised equipment } \\
\text { Materials handling equipment } \\
\text { Containers/packaging } \\
\text { The manufacturing plant } \\
\text { Testing and inspection equipment }\end{array}$ \\
\hline $\begin{array}{l}\text { Human } \\
\text { skills }\end{array}$ & $\begin{array}{l}\text { The workforce and their } \\
\text { skills and experience. }\end{array}$ & $\begin{array}{l}\text { Skills directly related to the } \\
\text { manufacture, or support skills }\end{array}$ \\
\hline Organisation & $\begin{array}{l}\text { Principles, practices and } \\
\text { arrangements used within } \\
\text { the supplier. }\end{array}$ & $\begin{array}{l}\text { work conventions - quality } \\
\text { circles, JIT, etc. } \\
\text { work organisation - team } \\
\text { working, cellular production, } \\
\text { work hours etc. } \\
\text { work facilitation - production } \\
\text { control and planning systems etc. } \\
\text { work evaluation - quality control } \\
\text { methods, SQC, monitoring } \\
\text { systems etc. } \\
\text { work modification- feedback, } \\
\text { rework policies, etc. }\end{array}$ \\
\hline Research & $\begin{array}{l}\text { Research areas the supplier } \\
\text { is currently working on. }\end{array}$ & $\begin{array}{l}\text { In materials, process, product and } \\
\text { business activities }\end{array}$ \\
\hline $\begin{array}{l}\text { Financial } \\
\text { resources }\end{array}$ & $\begin{array}{l}\text { The financial position of the } \\
\text { company. }\end{array}$ & $\begin{array}{l}\text { Balance sheet/ profit and loss } \\
\text { figures and accounting ratios }\end{array}$ \\
\hline $\begin{array}{l}\text { Information } \\
\text { transfer }\end{array}$ & $\begin{array}{l}\text { Facilities for communicating } \\
\text { with the OEM. }\end{array}$ & $\begin{array}{l}\text { File transfer format, CAD/CAM } \\
\text { packages, office packages, } \\
\text { automatic invoicing }\end{array}$ \\
\hline
\end{tabular}




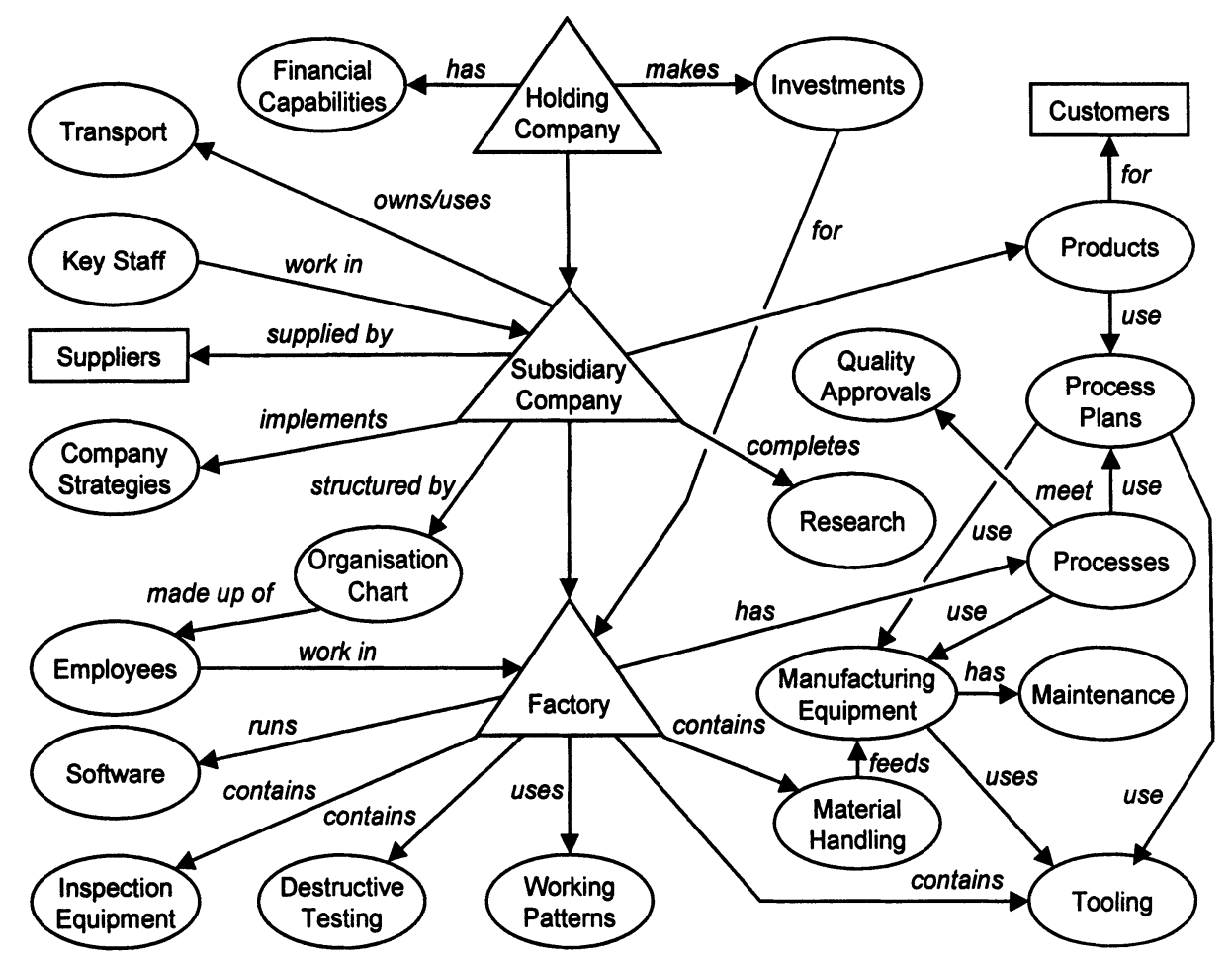

Figure 3 - Structure of the Supplier Capability Model

\section{SUPPLIER CAPABILITY MODEL SUPPORT FOR PRODUCT DEVELOPMENT}

As previously noted, there are three key user groups of the supplier capability model and their information requirements vary with respect to the mode of product development and the stage of supplier selection. There are therefore a number of different design scenarios that the supplier capability model must support (Figure 4).

In Design Scenario 1, the supplier has manufactured the original design for the OEM and is retained as the sole source for a variant or an updated design of the existing component. In this instance the designer at the OEM needs to design within the constraints of the manufacturing processes currently used by the supplier or at least know when the design is outside the constraints of the existing process. The supplier capability model supports this scenario by maintaining the process plan for the original part with links to the manufacturing equipment and tooling that are employed. These enable the designer or manufacturing engineer to examine the constraints of the machines and tooling used to produce the existing part and so be aware of when the new design exceeds the ability of the current process plan.

In Design Scenario 2, the end customer has provided the product owner with the functional specification for a new product or a variant design and a new supplier is selected prior to the design of the component. To aid procurement staff in identifying a 
suitable supplier, the model supports the storage of the information that is typically used during supplier selection. During conceptual design the designers should know what processes the supplier has capability in and be able to consider the major limitations of the processes. During detail design the designer should bear in mind the potential process plans that could be used to manufacture the part using the suppliers' facilities and the limitations of the resources. The model supports these activities by containing details of available processes and associated manufacturing equipment

Design Scenario

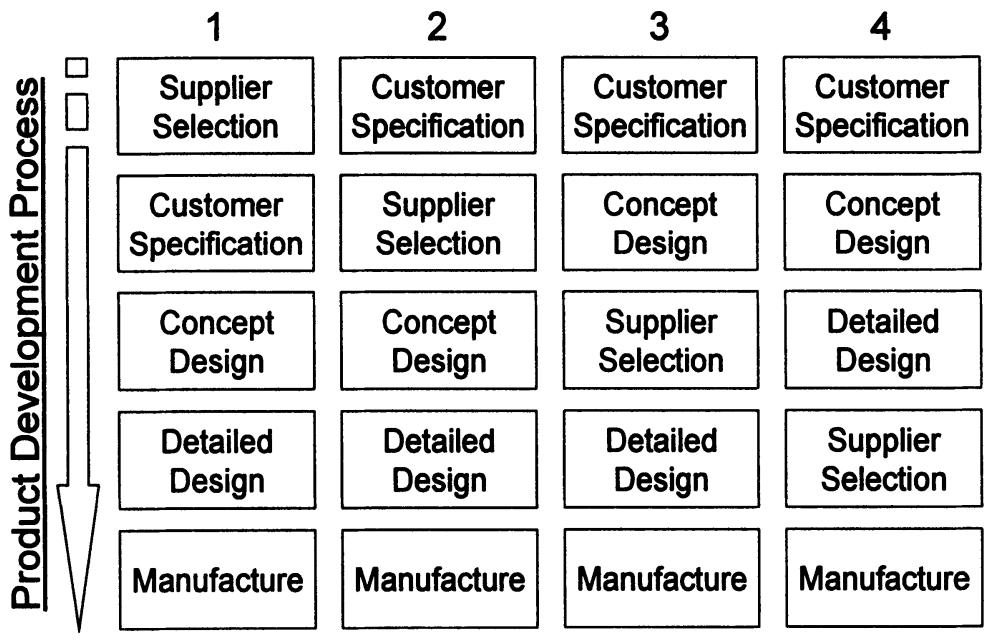

Figure 4-Design scenarios

In Design Scenario 3, the product owner has selected a concept and knows what material the component is to be manufactured of and more or less which processes are to be used to give the desired attributes of the component. This typically occurs with major contracts associated with new and variant products, where the supplier is selected at a suitable stage to allow their input during component detailing. The model supports design, manufacturing engineering and procurement staff essentially as in the second scenario.

In Design Scenario 4, the supplier is selected after the product owner has produced the detail design. This is typical of the handling of the smaller build-to-print contracts associated with new and variant products. The key support that is provided by the supplier capability model in this scenario is to enable the establishment of the industrial norm of manufacturing capabilities, so as to allow the design to be as generic as possible. The design team may also wish to use the model in this way even if the supplier has been selected at an earlier stage, so as to ease the subsequent transfer of any contracts such as may be required for commercial reasons. It can be noted that there has been a world-wide shortage of aerospace manufacturing capacity over the last two years and product owners have experienced difficulties in finding suppliers for new development projects. It may be necessary to proceed with design programme without completing supplier selection at the desired time. The supplier capability model assists both the location of suppliers and the practice of design for manufacture. 
The above scenarios have focused on the benefits available to the product owner. However, suppliers would also benefit from the model because it can provide an industrial standard for representing their capability. The model can act as a checklist for suppliers to develop their expertise. If administered by an acceptable industry association, the model can also be the basis for industry wide benchmarking and improvement programmes.

\section{IMPLEMENTATION OF THE SUPPLIER CAPABILITY MODEL}

The INDEMAND database (Figure 1) has been prototyped using proprietary relational database software and is structured similarly to the model. Internet technology was used to ease the population and maintenance of the database. The prototype system provides an inexpensive and easy to maintain means of collecting the information than manual data collection. It places the responsibility for maintaining capability information with the suppliers. It is observed that it is in the interest of the suppliers to provide capability information to the OEM. In addition, the structured HTML pages may also be reused by suppliers in their own Intranets. The construction of the framework is discussed in greater detail by Roy (Roy 1998).

\section{CONCLUSIONS}

This paper has reported on the development of a generic capability model for capturing supplier information to support product development in the extended enterprise. The specific industrial requirements of the civil aircraft sector have been outlined and the development of the model has been discussed. It has been described how the model may be used to support product development. The model aids design for manufacture within the OEM:

- In variant and new product design, by supporting access to details of the processes and manufacturing facilities of an individual supplier.

- In variant and new product design, by supporting the establishment of the industrial norm of manufacturing capabilities.

- In variant and continuous design, by supporting access to details of the processes and resources being used to make existing parts.

The model further benefits suppliers by:

- Providing a single, standard form for representing manufacturing capabilities, which could be used with the entire customer base.

- Enabling an increase in awareness of the current industrial norm of capabilities, which may be utilised in identifying areas for further developing individual supplier expertise.

The supplier capability model presented in this paper has been implemented, in prototype form, using relational database and Internet technology. Work is continuing with industry to further develop and establish industrial consensus on the supplier capability model and its use. 


\section{ACKNOWLEDGEMENTS}

The work described in this paper forms part of the UK Engineering and Physical Sciences Research Council (EPSRC) support project INDEMAND, GR/K95758.

\section{REFERENCES}

1 Bond A. and Ricci R. (1992) 'Co-operation in aircraft design', Research in Engineering Design, Vol. 4, pp. 115-130.

2 Boothroyd, G., Dewhurst, P. and Knight, W. (1994) Product Design for Manufacture and Assembly, Marcel-Dekker.

3 Busby J.S. and Fan I.-S., (1993) 'The extended manufacturing enterprise : its nature and its needs', International Journal of Technology Management, Vol. 9, Nos. 3/4/5, pp. 294-308.

4 Candadai, A., Herrmann J.W. and Minis, I. (1996) 'Application of group technology in distributed manufacturing', Journal of Intelligent Manufacturing, Vol. 7, No. 4, pp. 271-291.

5 Chang, T.C. (1990) Expert Process Planning for Manufacturing, Addison-Wesley.

6 Cooper, S.C., Fan, I.-S., Sehdev, K., Ward, N.J. and Williams, G.M. (1998) 'Process modelling the design of complex products in global enterprises', International Journal of Computer Applications in Technology, Vol. 11, No. 6, pp. 398-408.

7 Corbett J, Dooner M, Meleka J and Pym C. (1991) Design for Manufacture, Addison-Wesley.

8 Court, A. (1995) The Classification and Modelling of Information for Engineering Designers, $\mathrm{PhD}$ Thesis, University of Bath.

9 Court, A., Culley, S. and McMahon, C. (1993) A Survey of Information Storage and Access Amongst Engineers, University of Bath.

10 Dickson, G.W. (1966) 'An analysis of vendor selection systems and decisions', Journal of Purchasing, Vol. 2, pp. 5-17.

11 Ellram, L.M. (1990) 'The supplier selection decision in strategic partnerships', Journal of Purchasing and Materials Management, Vol. 26, No. 3, pp. 8-14.

12 Konda, S., Monarch, I., Sarget, P. and Subrahmanian, E. (1992) 'Shared memory in design: a unifying theme for research and practice', Research in Engineering design, Vol. 4, pp. 23-42.

13 Kuffner, T. and Ullman, D. (1991) 'The information requests of mechanical engineers', Design Studies, Vol. 12, No. 1, pp. 42-50.

14 Minis, I., Herrmann, J.W. and Lam, G. (1996) A Generative Approach for Design and Partner Selection for Agile Manufacturing, Technical Research Report T.R. 96-81, University of Maryland.

15 Molina, A., Ellis, T.I.A., Young, R.I.M. and Bell, R. (1994) 'Modelling manufacturing capabilities to support concurrent engineering', Concurrent Engineering - Research and Applications, Vol. 3, No. 1.

16 Naish, J.C., Mill F.G. and Salmon J.C. 'Implementation of process capability models to support computer aided process planning', Proceedings of the Thirteenth National Conference on Manufacturing Research, 9-11 September 1997, Glasgow, UK, pp. 275-279.

17 Roy, R., Cooper, S.C., Fan, I.-S., Sehdev, K. and Ward, N.J. (1998) 'Management of supplier capability information in the extended enterprise using internet technology', in Fukuda, S. and Chawdry, P.K. (eds.), CE98 - advances in concurrent engineering, 15-17 July 1998, Tokyo, Japan, pp. 137-144.

18 South Carolina Research Authority (SCRA) (1998) 'Group technology selection system,' http://www.ramp.scra.org/rampgtss.html (21 April 1998).

19 Vernadat, F. (1996) Enterprise Modelling and Integration - Principles and Applications, Chapman and Hall.

20 Weber, C. and Current, J.R. (1993) 'A multi-objective approach to vendor selection', European Journal of Operational Research, Vol. 86, pp. 173-184. 